\title{
O TESTE IMUNOENZIMÁTICO ELISA NO LÍQUIDO PERICÁRDICO: NOVO MÉTODO PARA O DIAGNÓSTICO POST-MORTEM DA DOENÇA DE CHAGAS
}

\author{
Ademir Rocha, José Roberto Mineo, Edison Reis Lopes, José Carlos Araújo Bessa, \\ Ana Paula Ferreira, Abílio José Segadães Filho, Térclo Gonçalves de Menezes e \\ Maria Cecília Costa
}

\begin{abstract}
Realizou-se o teste imunoenzimatico ELISA, paralelamente à reação de imunofluorescência, para a deteção de anticorpos anti-Trypanosoma cruzi, em 137 amostras de líquidos pericárdicos humanos, colhidos na necrópsia. Os resultados foram cotejados com os achados anatomopatologicos. Observou-se que: (1) os dois testes foram positivos em 30 casos e negativos em 105; (2) o teste ELISA foi positivo em 2 casos nos quais a imunofluorescência revelou-se negativa; num desses casos, havia sinais morfologicos de doença de Chagas; (3) a média geométrica dos titulos obtidos com o teste ELISA foi significativamente maior que a da imunofluorescência; (4) o indice de concordância entre os dois testes apresentou o valor de 0,985. O presente relato parece-nos inédito quanto ao uso do teste imunoenzimático no líquido pericárdico para o diagnóstico postmortem da doença de Chagas.
\end{abstract}

Palavras chaves: Elisa. Teste imunoenzimático. Liquido pericárdico. Doença de Chagas.

$O$ líquido pericárdico tem-se prestado ao diagnóstico post-mortem da doença de Chagas, como material para a realização de certas reações que visam detectar anticorpos anti-Trypanosoma cruzi. Durante anos, nele praticou-se apenas a reação de Guerreiro e Machado; vieram depois a hemaglutinação passiva e a imunofluorescência indireta (IF), testes que, em mujtas pesquisas, revelaram-se, isoladamente, mais eficientes que aquela reação (revisão em Lopes e $\operatorname{cols}^{9}$ ). A utilização de dois ou três testes em cada caso permitiu maior eficiência e segurança nos diagnósticos, praticamente eliminando os falsos negativos (que eram freqüentes quando se realizava apenas a reação de Guerreiro e Machado).

De algum tempo a esta parte, vem utilizando-se - teste imunoenzimático ELISA ("enzyme-linked immunosorbent assay") no soro, para diagnósticos diversos ${ }^{3612}$; recentemente, Costa \& cols ${ }^{4}$ o praticaram no líquor, para a caracterização de neurocisticercose. Partindo da premissa de que o referido teste pudesse ser efetuado também no líquido pericárdico, para a deteç̧ão da tripanossomose cruzi, decidimos avaliar sua eficácia em líquidos colhidos na necrópsia,

Endereço para correspondência: Ademir Rocha, Setor de Anatomia Patológica, Centro de Ciências Biomédicas, Departamento de Ciências Fundamentais para a Saúde, Universidade Federal de Uberlândia. Av. Pará 1720 - Campus Umuarama - 38400 Uberlândia, MG.

Trabalho das disciplinas de Patologia, Medicina Legal e Imunologia do Centro de Ciências Biomédicas da Universidade Federal de Uberlândia, e de Patologia e Medicina Legal da Faculdade de Medicina do Triângulo Mineiro (Uberaba). Realizado com auxilio do CNPq do Brasil.

Recebido para publicação em 16/12/85. cotejando os resultados com os achados anatomopatológicos. A finalidade do presente trabalho é mostrar e comentar os dados obtidos.

\section{MATERIAL E MÉTODOS}

O material utilizado consta de líquidos pericárdicos obtidos de 137 individuos necropsiados nos serviços de Anatomia Patológica do Centro de Ciências Biomédicas da Universidade Federal de Uberlândia e da Faculdade de Medicina do Triângulo Mineiro (Uberaba), e nos postos médico-legais das duas cidades. Efetuaram-se, em cada líquido, os testes: (1) de imunofluorescência indireta para $T$. cruzi, segundo a técnica de $\mathrm{Camargo}^{2}$; consideraram-se positivas as reações com título igual ou superior a 20 ; (2) ELISA, de acordo com a técnica de Engvall e Perlmann ${ }^{5}$, modificada e descrita a seguir.

Para o teste imunoenzimático, empregou-se antígeno solúvel de formas epimastigotas de $T$. cruzi (cultivado em meio LIT), obtido conforme o método descrito por Maekelt ${ }^{11}$. $O$ conjugado imunoenzimático foi preparado pela conjugação de anticorpos antiIgG humana com peroxidase (horseradish peroxidase, tipo VI, Sigma Chem. Co., St. Louis, MO), segundo o método de Nakane e Kawaoi ${ }^{13}$. Os testes foram feitos em placas de poliestireno, como suporte sólido para a preparação antigênica; as placas foram sensibilizadas com solução contendo $20 \mu \mathrm{g}$ de proteína do extrato solúvel diluído em tampão carbonato-bicarbonato $0,06 \mathrm{M} \mathrm{pH} 9,6$, e incubadas por 18 horas a $4{ }^{\circ} \mathrm{C}$. As amostras de líquido pericárdico foram diluidas em solução salina tamponada com fosfatos (PBS) $0,01 \mathrm{M}$, pH 7,2, contendo "tween 20" na concentração de 
Rocha A, Mineo JR, Lopes ER, Bessa JCA, Ferreira AP, Segadães Fo AJ, Menezes TG de, Costa MC. O teste imunoenzimático Elisa no líquido pericárdico: novo método para diagnóstico post-mortem da doença de Chagas. Revista da Sociedade Brasileira de Medicina Tropical 20: 213-216, Out-Dez, 1987

$0,05 \%$, a partir de $1 / 20$, na razão 2 , até a diluição de $1 / 2560$. Essas diluiçōes foram adicionadas às placas sensibilizadas e incubadas por 45 minutos a $37^{\circ} \mathrm{C}$. Após esse periodo, as placas foram lavadas no mesmo solvente (PBS-"tween 20") por três vezes de 5 minutos cada e incubadas na diluição ótima do conjugado por 45 minutos a $37^{\circ} \mathrm{C}$. Depois de nova série de três lavagens, acrescentou-se o substrato (que consistiu de solução de peróxido de hidrogênio e ácido 5-aminosalicílico) o qual foi incubado por uma hora à temperatura ambiente. A atividade enzimática foi avaliada por leitura visual; considerou-se como título de cada amostra a máxima diluição na qual se notava uma maior intensidade de coloração quando comparada com a menor diluição das amostras de líquido pericárdico não-reagentes. Títulos de valor igual ou superior a 20 foram tidos como positivos.

\section{RESULTADOS}

A Tabela 1 mostra os resultados dos testes Elisa e de IF no liquido pericárdico, e os correspondentes achados da anatomia patológica em relação à presença ou ausência de sinais de doença de Chagas. Nota-se que os dois testes foram reagentes em 135 casos e discrepantes em apenas dois (Elisa positivo e IF negativa); entre os 30 positivos, a anatomia patológica não caracterizou a tripanossomose em 5 , enquanto para os dois discrepantes havia evidência morfológica de doença em um.

Tabela 1 -Elisa e imunofluorescência no líquido pericárdico de indivíduos com e sem sinais morfologicos de doença de Chagas.

\begin{tabular}{cccc}
\hline \multicolumn{2}{c}{ Sorologia* } & & Anatomia \\
Elisa & IF & Patologica** & $\begin{array}{c}\text { Total de } \\
\text { Casos }\end{array}$ \\
\hline+ & + & + & 25 \\
+ & + & - & 5 \\
- & - & - & 105 \\
+ & - & + & 1 \\
+ & - & - & 1 \\
\hline
\end{tabular}

*Elisa (+) e IF $(+)=$ titulos $\geq 20$

** Anatomia patológica $(+)=$ presença de cardite chagásica crônica e/ou "megas".

A Tabela 2 apresenta os resultados comparativos dos titulos obtidos nos dois testes. A análise dos valores observados pelo teste " $t$ " revelou que a média geométrica dos títulos do teste Elisa foi significativamente maior que a da IF.

Tabela 2-Resultados comparativos entre os titulos obtidos nos testes Elisa-IgGe imunofluorescência-IgGem 137 amostras de líquidos pericárdicos submetidos ao diagnóstico da doença de Chagas.

\begin{tabular}{|c|c|c|c|c|c|c|c|c|c|c|}
\hline \multirow{2}{*}{$\begin{array}{l}\text { Titulos } \\
\text { Imunofluores- } \\
\text { cência-IgG }\end{array}$} & \multicolumn{9}{|c|}{ Títulos-Elisa-IgG } & \multirow{2}{*}{ Total } \\
\hline & $<20$ & 20 & 40 & 80 & 160 & 320 & 640 & 1280 & 2560 & \\
\hline 20 & 105 & & 1 & 1 & & & & & & 107 \\
\hline 20 & & 1 & & & & & & & & 1 \\
\hline 40 & & & 1 & & & 1 & & & 1 & 3 \\
\hline 80 & & & & & & 3 & 2 & & & 5 \\
\hline 160 & & & & 2 & & & 1 & 4 & & 7 \\
\hline 320 & & & 1 & & 1 & 1 & 1 & 2 & 1 & 7 \\
\hline 640 & & & & & 2 & & 1 & 1 & & 4 \\
\hline 1280 & & & & & & & 1 & 1 & & 2 \\
\hline 2560 & & & & & & 1 & & & & 1 \\
\hline Total & 105 & 1 & 3 & 3 & 3 & 6 & 6 & 8 & 2 & 137 \\
\hline
\end{tabular}

\section{DISCUSSÃO}

As reações imunoenzimáticas constituem um novo caminho nas técnicas imunológicas, iniciado por Nakane e Pierce ${ }^{14}$ e Avrameas e Uriel ${ }^{1}$. Estes autores mostraram que, além dos fluorocromos e radionúclides, outras substâncias, como as enzimas, poderiam ligar-se a moléculas de imunoglobulinas, formando conjugados imunoenzimáticos. Voller e cols ${ }^{16} 17$ e Ruitenberg e Van Knapen ${ }^{15}$ iniciaram a aplicação destas reações em doenças infecciosas e parasitárias. Desde então, observou-se o uso de tais técnicas para o diagnóstico, in vivo, da doença de Chagas ${ }^{3}$, toxoplasmose $^{12}$, cisticercose $e^{4}$, brucelose $e^{6}$, rotavirose ${ }^{18}$ etc. 
Rocha A, Mineo JR, Lopes ER, Bessa JCA, Ferreira AP, Segadães Fo AJ, Menezes TG de, Costa MC. O teste imunoenzimático Elisa no líquido pericárdico: novo método para diagnóstico post-mortem da doença de Chagas. Revista da Sociedade Brasileira de Medicina Tropical 20: 213-216, Out-Dez, 1987

Vantagens das reações enzimáticas têm sido referidas, em relação à sensibilidade, especificidade, reprodutibilidade e custo 351617 .

Com respeito ao líquido pericárdico, parece-nos que o presente relato é inédito quanto ao uso do teste Elisa para o diagnóstico post-mortem da doença de Chagas. Este método vem somar-se à reação de fixação do complemento, hemaglutinação e imunofluorescência, já empregadas com igual finalidade 78910 ; representa um novo dado que permitirá maior segurança no referido mister.

Nos seis casos em que a reação imunoenzimática foi positiva (com positividade também da IF em 5), mas não se evidenciaram aspectos anatomopatológicos da forma crônica da tripanossomose (com positividade também da IF em 5), três alternativas parecemnos viáveis: (1) os pacientes tinham anticorpos apenas como sinais de infecção pregressa, sem lesões atuais relacionadas à tripanossomose; (2) o aprofundamento da pesquisa morfológica (especialmente pelo exame de um número maior de cortes do coração) poderia revelar alterações devidos à enfermidade; (3) a positividade sorológica dever-se-ia a reação cruzada com outra infecção (como lues, leishmaniose ou hanseníase, embora não se tenham constatado elementos para tais diagnósticos).

\section{SUMMARY}

The immunoenzymatic assay (Elisa) in the pericardial fluid: a new method for the post-mortem diagnosis of Chagas' disease. The immunoenzymatic assay (Elisa) was made in parallel with the immunofluorescence reaction, for the detection of anti-Trypanosona cruzi antibodies in 137 samples of human pericardial fluids, collected at necropsy. The results were compared with those of anatomopathological exams.

We observed that: (1) the two tests were positive in 30 cases and were negative in 105 ones; (2) the Elisa test was positive in 2 cases in which the immunofluorescence was negative; in one of them we found morphological evidences of Chagas' disease; (3) the geometric mean of titles with Elisa was statistically superior to that obtained with immunofluorescence test; (4) the rate of concordance between the two tests was 0.985 .

This appears to be the first published report about the use of immunoenzymatic assay in the pericardial fluid for the post-mortem diagnosis of Chagas' disease.

Key words: Elisa. Immunoenzymatic test. Pericardial fluid. Chagas' disease.

\section{AGRADECIMENTOS}

Os autores são gratos à Srta. Sônia Maria Mendonça Gonzaga pelo serviço datilográfico.

\section{REFERÊNCIAS BIBLIOGRÁFICAS}

1. Avrameas S, Uriel J. Méthode de marquage d'antigénes et d'anticorps avec des enzymes et son application en immunodifusion. Comptes Rendus des Seances de l'Academie des Sciences (Paris) 262: 2543-2545, 1966.

2. Camargo ME. Fluorescent antibody test for the diagnosis of American trypanosomiasis. Technical modification employing preserved culture forms of Trypanosoma cruzi in a slide test. Revista do Instituto de Medicina Tropical de São Paulo 8: 227-234, 1966.

3. Camargo ME, Ferreira AW, Mineo JR, Carraro FM, Brodskyn CI. A practical immunoenzymatic test for routine serologic diagnosis of Chagas' disease. Resumos do Congresso Internacional sobre Doença de Chagas (Rio de Janeiro), p. 218, 1979.

4. Costa JM, Ferreira AW, Makino MM, Camargo ME. Spinal fluid immunoenzymatic assay (Elisa) for neurocysticercosis. Revista do Instituto de Medicina Tropical de São Paulo 24: 337-341, 1981.

5. Engvall E, Perlmann P. Enzyme-linked immunosorbent assay (Elisa). III. Quantitation of specific antibodies by enzyme labeled anti-immunoglobulin in antigen-coated tubes. Journal of Immunology 109: 129-135, 1972.

6. Gomes MA, Mineo JR, Rezende MAC, Anna WC, Pereira VJ, Beicher AMAH, Naves EA, Souza MA. Pesquisa de anticorpos IgG e IgM anti-Brucella abortus por técnicas imunoenzimáticas em amostras de soros de trabalhadores em frigorificos da cidade de Uberlândia (MG). Anais do XXI Congresso da Sociedade Brasileira de Medicina Tropical, São Paulo, pp. 84-85, 1985.

7. Hial V, Almeida HO, Chapadeiro ER. Estudo comparativo da reaçāo de Guerreiro e Machado nos líquidos pericárdico e peritonial. Revista Goiana de Medicina 16: 185-188, 1970.

8. Lopes ER, Batista SM, Chapadeiro E, Almeida HO, Rocha A, Pires J. Estudo comparativo entre o teste de hemaglutinação e a reação de fixação do complemento no líquido pericárdico de chagásicos crônicos. Revista do Instituto de Medicina Tropical de São Paulo 15: 57-59, 1973.

9. Lopes ER, Chapadeiro E, Batista SM, Cunha Jr JG, Rocha A, Miziara L, Ribeiro JU, Patto RJ. Post-mortem diagnosis of chronic Chagas' disease: comparative evaluation of three serological test on pericardial fluid. Transactions of the Royal Society of Tropical Medicine and Hygiene 72: 244-246, 1978.

10. Lopes ER, Chapadeiro E, Furtado JHM, Hial V, Campos Netto A. Reação de Guerreiro e Machado no liquido pericárdico de portadores de cardite chagásica crônica. Revista do Instituto de Medicina Tropical de São Paulo 8: $60-61,1966$

11. Maekelt GA. Die komplementbindungsreaktion der Chagaskrankheit. Zeitschrift für Tropenmedizin und Parasitologie 2: 152-186, 1960.

12. Mineo JR, Camargo ME, Ferreira AW. Enzyme-linked immunosorbent assay for antibodies to Toxoplasma gondii - polisaccharides in human toxoplasmosis. Infection and Immunity 27: 283-287, 1980.

13. Nakane PK, Kawaoi A. Peroxidase-labeled antibody. A new method of conjugation. Journal of Histochemistry and Cytochemistry 22: 1084-1091, 1974. 
Rocha A, Mineo JR, Lopes ER, Bessa JCA, Ferreira AP, Segadães Fo AJ, Menezes TG de, Costa MC. O teste imunoenzimático Elisa no liquido pericárdico: novo método para diagnóstico post-mortem da doença de Chagas. Revista da Sociedade Brasileira de Medicina Tropical 20: 213-216, Out-Dez, 1987

14. Nakane PK, Pierce GB. Enzyme labeled antibody. Preparation and application for the localization of antigens. Journal of Histochemistry and Cytochemistry 14: 929$931,1966$.

15. Ruitenberg EJ, Van Knapen F. The enzyme-linked immunosorbent assay and its application to parasite infections. Journal of Infectious Diseases 136 (Suppl): 267 273, 1977.
16. Voller A, Bidwell DE, Huldt G, Bartlett A. Microplate enzyme-linked immunosorbent assay for Chagas' disease. The Lancet 1: 426-428, 1975.

17. Voller A, Bidwell DE, Bartlett A, Feck A, Perkings M, Oladehin B. A microplate enzymeimmunoassay for toxoplasma antibody. Journal of Clinical Pathology 29: 150$153,1976$.

18. Yolken RH. Avidin-biotin radioimmunoassay for human rotavirus. Journal of Infectious Diseases 148: 942, 1983. 